\title{
DNA Gel Particles: Particle Preparation and Release Characteristics
}

\author{
M. Carmen Morán, ${ }^{* \dagger}$ M. Graça Miguel, ${ }^{\dagger}$ and Björn Lindman ${ }^{\dagger, \dagger}$ \\ Chemistry Department, Coimbra University, 3004-535 Coimbra, Portugal, and Physical Chemistry 1, \\ Lund University, P. O. Box 124, 22100 Lund, Sweden
}

Received March 7, 2007

\begin{abstract}
Aqueous mixtures of oppositely charged polyelectrolytes undergo associative phase separation, resulting in coacervation, gelation, or precipitation. This phenomenon has been exploited here to form DNA gel particles by interfacial diffusion. We report the formation of DNA gel particles by mixing solutions of DNA (either single-stranded (ssDNA) or double-stranded (dsDNA)) with solutions of cationic surfactant CTAB and solutions of the protein lysozyme. Swelling, surface morphology, and DNA release determinations indicate different interaction of ssDNA and dsDNA with both the surfactant and the protein. By using CTAB and lysozyme as the base material, the formation of a DNA reservoir hydrogel, without adding any kind of cross-linker or organic solvent, was demostrated.
\end{abstract}

\section{Introduction}

A novel nonviral vector for gene therapy is recognized as successful if it is biocompatible, capable of interacting with DNA, forms sufficiently small particles that can be formulated reproducibly, endocytosed, able to protect the complexed DNA from degradation during transport, and capable of delivering DNA to the target tisssue in sufficient quantity. ${ }^{1-3}$ Regarding this goal, some authors have developed a way to deliver DNA to the target cells by encapsulating it into a controlled-release system. For this purpose, poly(lactic-co-glycolic acid) (PLGA) microspheres have been used. ${ }^{4-6}$ However, the problems encountered in reaching this goal were related not only to the microencapsulation technologies but also to the intrinsic nature of polyesters. Indeed, the PLGA microencapsulation technologies imply the use of organic solvents and high-energy sources, thus leading to a significant degradation of the encapsulated macromolecule during the course of the PLGA hydrolysis. Following the identification of these problems, a number of strategies aimed at either modifying the encapsulation techniques or using new encapsulation materials were explored. Chitosan microspheres containing plasmid DNA were prepared by the complex coacervation method in the absence ${ }^{7}$ or presence of a DNA condensing agent. ${ }^{8}$

Interestingly, interactions between oppositely charged surfactants and polyelectrolytes in aqueous solutions can lead to associative phase separation, where the concentrated phase assumes the form of a viscous liquid, gel, or precipitate. This behavior has been exploited to form gel particles, which have been prepared by the dropwise addition of a cellulose-based polycation solution (chitosan, $\mathrm{N}, \mathrm{N}, \mathrm{N}$-trimethylammoniumderivatized hydroxyethyl cellulose (Amerchol JR-400) $)^{9-12}$ to

\footnotetext{
* Corresponding author. E-mail: mcarmen@qui.uc.pt.

Coimbra University.

$\doteqdot$ Lund University.

(1) Ledley, F. D. Pharm. Res. 1996, 13, 1595-1614.

(2) Pack, D. W.; Putnam, D.; Langer, R. Biotechnol. Bioeng. 2000, 67, $217-$ 223.

(3) Davis, M. E. Curr. Opin. Biotechnol. 2002, 13, 128-131.

(4) Walter, E.; Moelling, K.; Pavlovic, J.; Merkle, H. P. J. Controlled Release 1999, 61, 361-374.

(5) Mohamed, F.; van der Walle, C. F. Int. J. Pharm. 2006, 311, 97-107.

(6) Csaba, N.; Caamaño, P.; Sánchez, A.; Domínguez, F.; Alonso, M. J. Biomacromolecules 2005, 6, 271-278.

(7) OzBas-Turan, S.; Aral, C.; Kabasakal, L.; Keyer-Uysal, M.; Akbuga, J. J. Pharm. Pharm. Sci. 2003, 6, 27-32.

(8) Aral, C.; Akbuga, J. J. Pharm. Pharm. Sci. 2003, 6, 321-326.
}

anionic (sodium dodecyl sulfate (SDS), sodium perfluorooctanoate (FC7)) and catanionic (cetyltrimethylammonium bromide (CTAB)/sodium perfluorooctanoate (FC7) ${ }^{13}$ surfactant solutions.

The goal of this study is to investigate the formation of DNA gel particles at water/water emulsion-type interfaces by mixing DNA (either single- (ssDNA) or double-stranded (dsDNA)) with the cationic surfactant cetyltrimetrylammonium bromide (CTAB) or the protein lysozyme. Particles were characterized for swelling, dissolution behavior, surface morphology, and DNA release. The originality of this work consists of forming DNA reservoir hydrogels without adding any kind of cross-linker or organic solvent.

\section{Methods}

Materials. Deoxyribonucleic acid (DNA) from salmon testes (in the salt form, 1000 base pairs) was purchased from Sigma and used as received. The DNA concentrations were determined spectrophotometrically considering that for an absorbance of 1 at $260 \mathrm{~nm}$ a solution of dsDNA has a concentration of $50 \mu \mathrm{g} / \mathrm{mL}$ and a solution of ssDNA has a concentration of $40 \mu \mathrm{g} / \mathrm{mL} .{ }^{14}$ All DNA concentrations are presented in molarity per phosphate group (i.e., molarity per negative charge). The ratios of absorbance at 260 and $280 \mathrm{~nm}$ of the stock solutions were found to be between 1.8 and 1.9, which suggested the absence of proteins. ${ }^{15}$ Cetyltrimethylammonium bromide (CTAB), obtained from Sigma, was recrystallized with acetone and ethanol. Lysozyme from chicken egg white (molecular mass $14.3 \mathrm{kDa}$ ) was purchased from Sigma and used as received. All experiments were performed using Millipore Milli-Q deionized water (18.2 $\mathrm{M} \Omega \mathrm{cm}$ resistivity).

Particle Preparation. dsDNA stock solutions were prepared in $10 \mathrm{mM} \mathrm{NaBr}$ in order to stabilize the DNA secondary structure in

(9) Babak, V. G.; Merkovich, E. A.; Galbraikh, L. S.; Shtykova, E. V.; Rinaudo, M. Mendeleev Commun. 2000, 3, 94-95.

(10) Julia Ferres, M. R.; Erra, S. P.; Muñoz Liron, I.; Ayats Llorens, A. Procedure for Preparing Capsules and for Encapsulation of Substances. Patent No. ES2112150, Spain, 1998.

(11) Lapitsky, Y.; Kaler, E. W. Colloids Surf., A 2004, 250, 179-187.

(12) Lapitsky, Y.; Eskuchen, W. J.; Kaler, E. W. Langmuir 2006, 22, 63756379.

(13) Lapitsky, Y.; Kaler, E. W. Colloids Surf., A 2006, 282-283, 118-128.

(14) Sambrook, J.; Fritsch, E. F.; Maniatis, T. Molecular Cloning: A Laboratory Manual; Cold Spring Harbor Laboratory Press: Cold Spring Harbor, NY, 1989; Vol. 3, App. C.1.

(15) Saenger, W. Principles of Nuclei Structure; Springer-Verlag: NewYork, 1984. 


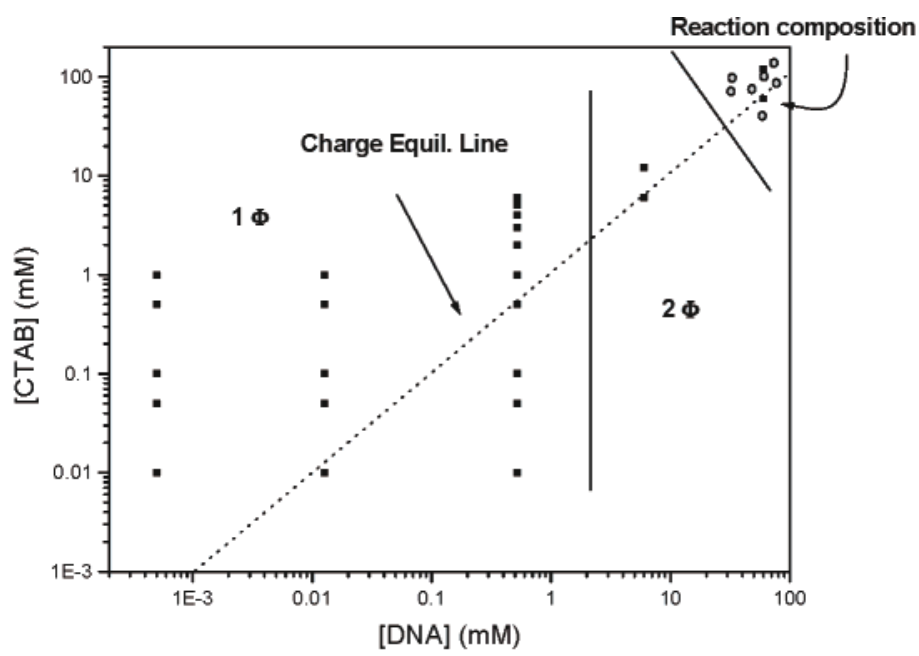

A

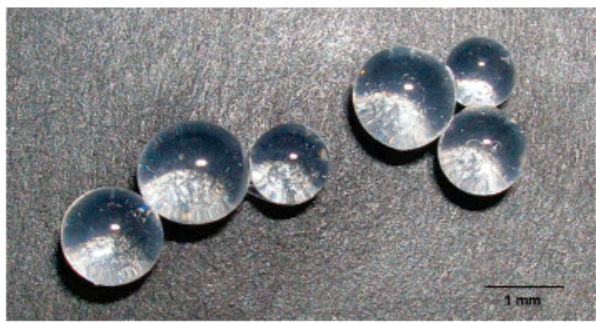

B

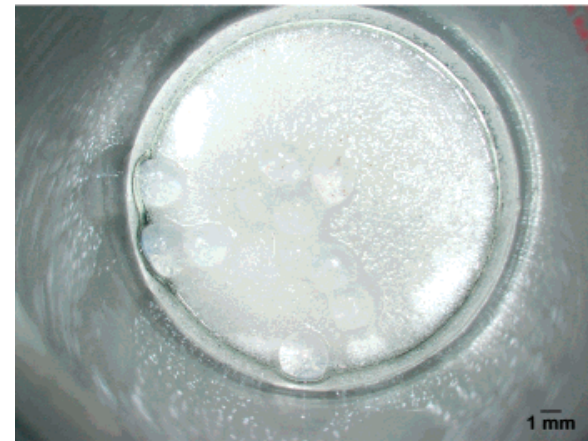

C

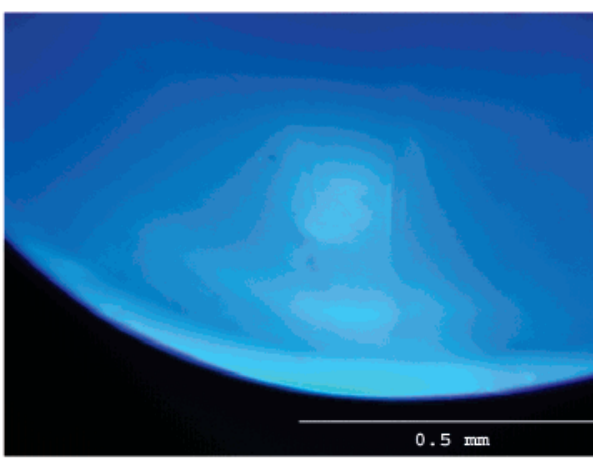

D

Figure 1. Formation of DNA gel particles: (A) Phase map of the CTAB/dsDNA/water mixture at $25^{\circ} \mathrm{C}$, where $1 \phi$ and $2 \phi$ indicate the one- and two-phase regions, respectively; (B) CTAB-dsDNA particles; (C) lysozyme-dsDNA particles; and (D) fluorescence micrograph of $\mathrm{CTAB}-\mathrm{dsDNA}$ particles in presence of fluorescent dye 4'-6-diamidino-2-phenyl-indole (DAPI).

its native B-form conformation. ${ }^{16}$ ssDNA stock solutions were prepared by thermal denaturation of dsDNA stock solutions at 80 ${ }^{\circ} \mathrm{C}$ for $15 \mathrm{~min}$ and then immediately dipping into ice for fast cooling to prevent renaturation. CTAB was dissolved in Milli-Q water, whereas lysozyme was dissolved in a $\mathrm{pH}$ 7.6 Tris $-\mathrm{HCl}$ buffer. DNA solutions were added dropwise via a 22 -gauge needle into gently agitated surfactant or protein solutions (1 to $2 \mathrm{~mL}$ ). Under optimal conditions, droplets from DNA solutions instantaneously gelled into discrete particles upon contact with the corresponding surfactant or protein solution. Thereafter, the particles were left to equilibrate in the respective solutions for a period of $2 \mathrm{~h}$. Then the particles were separated by filtration through a G2 filter and washed with $5 \times 8$ $\mathrm{mL}$ of Milli-Q water to remove excess salt.

Swelling and Dissolution Behavior of DNA Gel Particles. Studies were conducted in $10 \mathrm{mM}$ Tris $-\mathrm{HCl}$ buffer (pH 7.6). Particles (around $100 \mathrm{mg}$ ) were exposed to this dissolution media at an agitation

(16) Rosa, M.; Dias, R.; Miguel, M. G.; Lindman, B. Biomacromolecules 2005, 6, 2164-2171. rate of $40 \mathrm{rpm}$ using an ST 5 CAT shaking platform. At specific time intervals, the entire quantity of the dissolution medium was removed, and the particles were weighted. Then, new solution was added to maintain a clean environment. This procedure was repeated until the particles were completely dissolved. The data were then transformed into relative weight loss using the following equation

$$
\text { relative weight ratio }(\mathrm{RW})=\frac{W_{\mathrm{i}}-W_{t}}{W_{\mathrm{i}}}
$$

where $W_{\mathrm{i}}$ stands for the initial weight of the particles and $W_{t}$ stands for the weight of the particles at time $t$.

Scanning Electron Microscopy Imaging. Scanning electron microscopy (SEM) (Philips XL30- TMP) was used to evaluate both the outer and the inner surface morphologies of the particles. Prior to that, the particles were lyophilized overnight $\left(-46{ }^{\circ} \mathrm{C}, 0.035\right.$ mbar). All of the samples were stored under vacuum and taken out just before the SEM observation. The dried particles were viewed without sputter coating. 


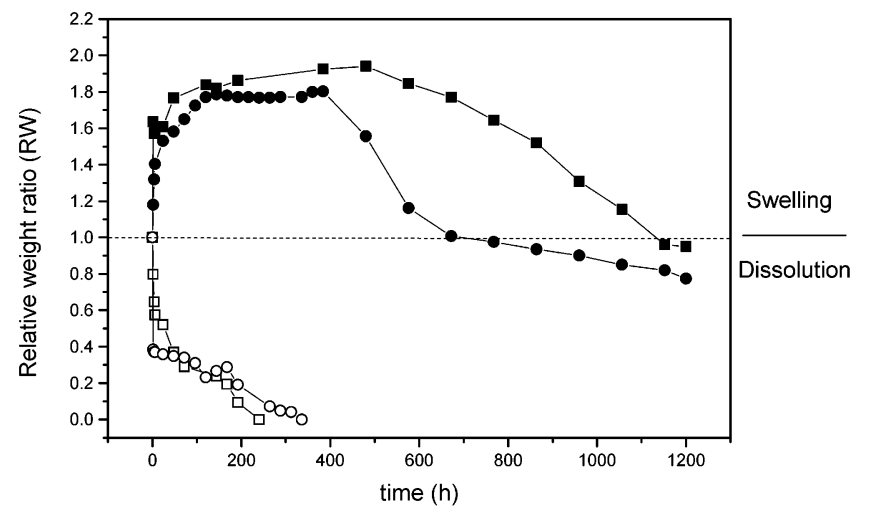

Figure 2. Relative weight ratio measurements performed on dsDNA-CTAB (ם), ssDNA-CTAB (•), dsDNA-lysozyme ( $\square$ ), and ssDNA-lysozyme $(O)$ particles after exposure to buffer solution (Tris- $\mathrm{HCl} \mathrm{pH}$ 7.6).

DNA Release Studies. DNA gel particles (around $100 \mathrm{mg}$ ) were suspended in $4 \mathrm{~mL}$ of $10 \mathrm{mM}$ Tris $-\mathrm{HCl}$ buffer ( $\mathrm{pH}$ 7.6). The samples were incubated at $25^{\circ} \mathrm{C}$ with gentle shaking $(40 \mathrm{rpm})$. At defined time intervals, the supernatant was collected, and particles were resuspended in fresh solution. DNA released into the supernatant was quantified by measuring the absorbance at $260 \mathrm{~nm}$ with a spectrophotometer (Jasco V-530 UV/vis spectrophotometer).

\section{Results and Discussion}

Particle Characterization. The formation of DNA gel particles was initially studied using mixtures of dsDNA with CTAB. The obtained phase map is depicted in Figure 1A. Single-phase $(1 \phi)$ solutions are observed in the polymer-poor and surfactant-poor regions of the phase map. On the polymer-rich side of the phase map, once charge equilibration was achieved, associative phase separation occurred $(2 \phi)$. Finally, in the limit of very high polymer concentrations, a solid gel-like material forms. The size of the resulting particle reflects the size of the parent drop and varies between 1 and $3 \mathrm{~mm}$ (Figure 1B). Similar behavior was observed when particles were formed using denatured DNA. In parallel fashion, DNA gel particles were also obtained by the dropwise addition of a DNA solution to a lysozyme solution. The resulting particles swell very quickly in water during the washing step, and their final size was around $3 \mathrm{~mm}$ (Figure 1C). Fluorescence microscopy studies using fluorescent dye 4',6'-diamidino-2phenylindole (DAPI) confirm the presence of DNA in the particles (Figure 1D).

Particle Swelling and Deswelling Kinetics. Gels are considered to have great potential as drug reservoirs. Loaded drugs would be released by diffusion from the gels or by erosion of them. Hence, the releasing mechanism can be controlled by the swelling or dissolution of the gels. ${ }^{17}$ Figure 2 shows the relative weight ratio of the different gel particles after exposure to a buffer solution (Tris- $\mathrm{HCl} \mathrm{pH} \mathrm{7.6).} \mathrm{Different} \mathrm{behaviors} \mathrm{were}$ observed with different cationic agents used. Lysozyme-DNA particles show a rapid, extensive weight loss that may also explain the rapid DNA release behavior of lysozyme-DNA particles (see below). However, in the case of CTAB-DNA particles there is a prominent increase in weight with time that may be attributed to water uptake from the media. It could be observed that there is a period of stability in the swollen state before dissolution starts. The zero-returned point, where the weight of the gel returns to its starting point, seems to be dependent on the conformation of the DNA used. In the case of particles containing ssDNA, it is around $600 \mathrm{~h}$. When particles are formed with 270.

(17) Nam, K.; Watanabe, J.; Ishihara, K. Eur. J. Pharm. Sci. 2004, 23, 261-

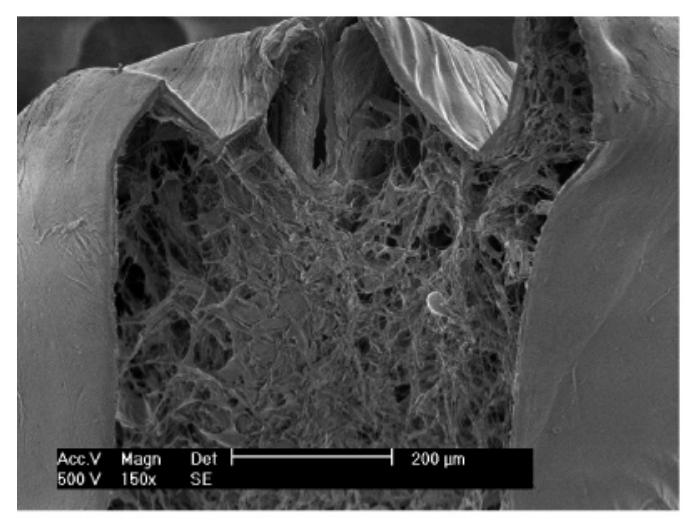

$\mathbf{A}$

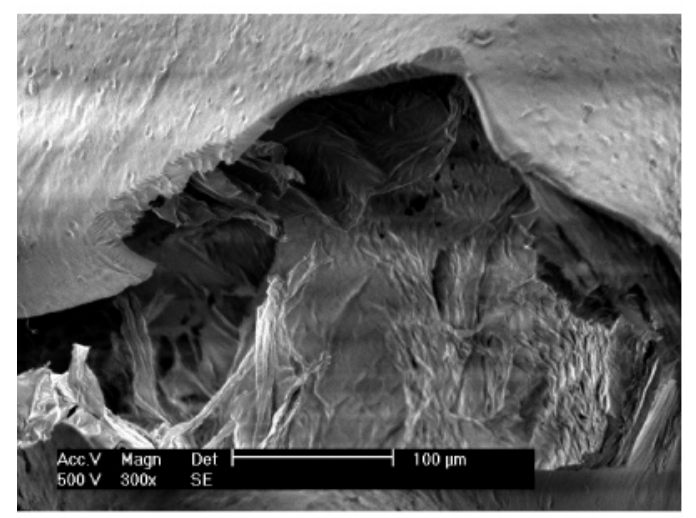

B

Figure 3. Scanning electron micrographs of cross-sections of individual particles: (A) CTAB - dsDNA and (B) CTAB - ssDNA particles.

dsDNA, particles experienced swelling over the entire time interval studied $(1200 \mathrm{~h})$. There is an interesting correlation of this behavior with the internal particle structure. Thus, Figure 3 shows the cross-sectional views of the scanning electron microscopy images of the $\mathrm{CTAB}-\mathrm{dsDNA}$ and $\mathrm{CTAB}-\mathrm{ssDNA}$ systems, respectively. Much larger pores and channel-like structures were found in the inner surface particles formed with native DNA. These results suggest that these particles are more porous and thus display a faster swelling response. The structure of the particles formed with denatured single-stranded DNA is rough and less open than that of particles formed with native DNA. This observation is consistent with the slower swelling response.

Kinetics of DNA Release. The release of DNA from different particles is illustrated in Figure 4. An examination of the DNA release kinetics shows strong differences between the cumulative DNA release from lysozyme and CTAB particles. LysozymeDNA particles exhibited a fast burst effect with 84 and $63 \%$ of the DNA released from particles containing native and denatured DNA, respectively, after $24 \mathrm{~h}$. Particles formed with the cationic surfactant showed no initial burst release; in the first $24 \mathrm{~h}$, only 2.9 and $3.5 \%$ of the DNA was released from the particles containing ds-DNA and ss-DNA, respectively.

The differences between the release of DNA from lysozyme and $\mathrm{CTAB}$ particles suggest that the interaction is much stronger in the case of the surfactant. This is consistent with a single electrostatic interaction. Whereas lysozyme has a net charge of +9 at neutral $\mathrm{pH}, \mathrm{CTAB}$ aggregates have a molar charge, which is an order of magnitude higher. Studies of complexes formed by interfacial diffusion between cationic chitosan and negatively charged SDS surfactant ${ }^{18}$ demonstrated that the capsule shells 


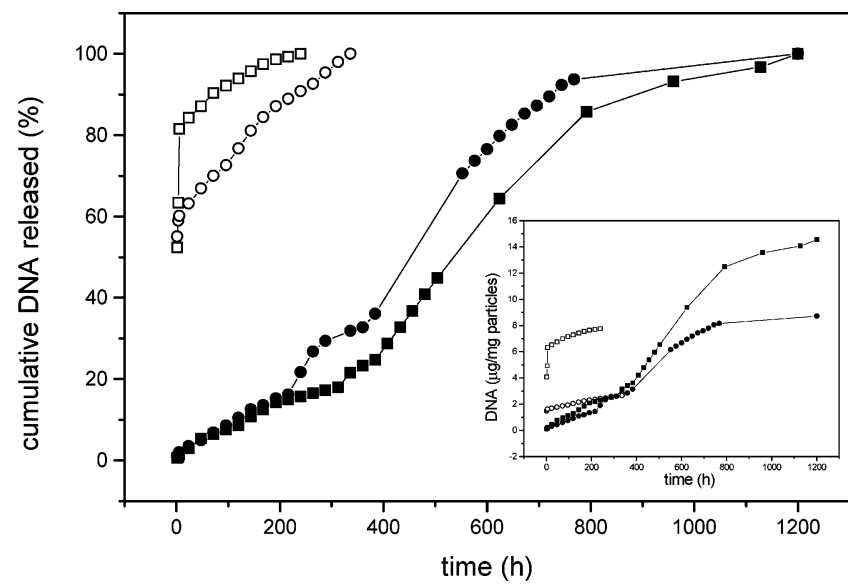

Figure 4. Release of DNA from dsDNA-CTAB (ם), ssDNACTAB (๑), dsDNA-lysozyme ( $\square$ ), and ssDNA-lysozyme (O) particles in $\mathrm{pH} 7.6 \mathrm{Tris}-\mathrm{HCl}$ buffer media.

obtained may be considered to be a physical network in which surfactant micelles form polycationic-multianionic electrostatic complexes as cross-link points. Scanning electron microscopy images support these results. In the present systems, the crosssection of the obtained particles showed a well-defined coreshell structure (Figure 3). However, particles obtained by the interactions of lysozyme were easily disrupted during the freezedrying process prior to the SEM procedure, confirming the weakness of their structure. Swelling and dissolution behavior also indicate differences in the structure of the complexes formed with surfactant and protein.

With respect to the observed differences between ss-DNA and ds-DNA in the release of either surfactant or protein (Figure 4 inset), the results are in agreement with previous studies, both experimental and theoretical, ${ }^{16,19-22}$ that have shown a stronger interaction with amphiphiles for ss-DNA that with those for

(18) Babak, V. G.; Merkovich, E. A.; Desbrières, J.; Rinaudo, M. Polym. Bull. 2000, $45,77-81$
ds-DNA. This fact strongly indicates the important role of hydrophobic interactions in DNA when the bases are more exposed, as in the case of ss-DNA.

\section{Concluding Remarks}

DNA gel particles were formed by interfacial diffusion on mixing DNA (either single-stranded (ssDNA) or double-stranded (dsDNA)) with CTAB or lysozyme. An analysis of the data indicates a different mechanism of interaction of ssDNA and dsDNA for both the surfactant and protein systems. The formation of a physical network in which surfactant micelles form polyanionic-multicationic electrostatic complexes as cross-link points seems to play an important role in the stabilization of DNA particles. For the first time, release studies from particles formed by interfacial diffusion were carried out. These studies revealed that DNA molecules are released from particles for a long period of time under an in vitro condition, which may provide an intracellular sustained release of DNA in vivo. Current studies are focused on characterizing the structure of these DNA gel particles and modifying the experimental conditions for further applications in gene transfection. Importantly, these particles represent a conceptual step in the design and development of new nonviral vectors for the delivery of therapeutic DNA.

Acknowledgment. This work was supported by grants from the Fundação para a Ciência e Tecnologia (FCT, POCTI/QUI/ 45344/02 and POCTI/QUI/58689/2004) and a grant from the EU Research Training Network, CIPSNAC (contract number MRTN-CT-2003-504932). SEM work was carried out in collaboration with Amilcar L. Ramalho. We are grateful to E. W. Kaler and Y. Lapitsky for fruitful discussions.

\section{LA700672E}

(19) Wallin, T.; Linse, P. J. Phys. Chem. B 1997, 101, 5506-5513.

(20) Wallin, T.; Linse, P. J. Phys. Chem. 1996, 100, 17873-17880.

(21) Wallin, T.; Linse, P. Langmuir 1996, 12, 305-314.

(22) Kwak, J. C. T. Polymer-Surfactant Systems; Marcel Dekker: NewYork, 